\title{
Desenvolvimento Sustentável: certeza em meio às incertezas
}

Sustainable Development: certainty in the face of uncertainties

Desarrollo sostenible: certeza ante las incertidumbres

Luiz Henrique Vieira da Silva Mestrando do Programa de Pós Graduação Stricto Sensu em Sustentabilidade, PUC Campinas, Brasil vieiraluiz77@gmail.com

\section{Samuel Carvalho De Benedicto} Coordenador do Programa de Pós Graduação Stricto Sensu em Sustentabilidade, PUC Campinas, Brasil samuel.debenedicto@gmail.com 


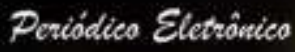

\section{RESUMO}

O debate acerca da possibilidade de um modelo global de desenvolvimento sustentável nunca configurou pauta tão urgente e preocupantemente necessária, sobremaneira quando a produção, o consumo e, consequentemente, a geração de resíduos, são questionados. $O$ assunto também é permeado por um cenário profundamente desigual, em que alguns povos são abastados enquanto outros amargam a inexistência de recursos para satisfazerem suas necessidades básicas e conferir-lhes oportunidades de desenvolvimento. Diante disso, levar a pauta ambientalista para pessoas pobres ou em ascensão social nos países em desenvolvimento, que anseiam pelo consumo, desponta como um desafio complexo e impreterível. Por meio de uma pesquisa exploratória, de caráter bibliográfico e documental, evidenciou-se que a resposta para esse problema passa, necessariamente, por uma transformação do paradigma criado pelo capitalismo industrial, através de modelos econômicos alternativos. Além disso, constatou-se que, em um cenário marcado por incertezas e conflitos, os Objetivos de Desenvolvimento Sustentável, que compõem a Agenda 2030, constituem um conjunto esquematizado de metas exequíveis no sentido do desenvolvimento sustentável, permitindo sua internalização em diferentes contextos, rumo não somente à produção e ao consumo conscientes, mas à construção de um mundo melhor.

PALAVRAS-CHAVE: Desenvolvimento Sustentável. Consumismo. Princípio da Precaução.

\begin{abstract}
The debate over the possibility of a global model of sustainable development has never configured such an urgent and worryingly necessary agenda, especially when production, consumption and, consequently, the generation of waste are questioned. The issue is also permeated by a profoundly unequal scenario, where some people are affluent while others embitter the lack of resources to meet their basic needs and provide them with opportunities for development. Given this, bringing the environmental agenda to poor or socially rising people in developing countries that yearn for consumption is a complex and unavoidable challenge. Through an exploratory research of bibliographic and documentary character, it was evidenced that the answer to this problem necessarily goes through a transformation of the paradigm created by industrial capitalism, through alternative economic models. Furthermore, it was found that, in a scenario marked by uncertainties and conflicts, the Sustainable Development Goals, which make up the 2030 Agenda for Sustainable Development, constitute a schematic set of achievable goals towards sustainable development, allowing their internalization in different contexts, towards not just conscious production and consumption, but building a better world.
\end{abstract}

KEYWORDS: Sustainable Development. Consumerism. Precautionary Principle.

\section{RESUMEN}

El debate sobre la posibilidad de un modelo global de desarrollo sostenible nunca ha configurado una agenda tan urgente y preocupantemente necesaria, especialmente cuando se cuestiona la producción, el consumo y, en consecuencia, la generación de residuos. El tema también está permeado por un escenario profundamente desigual, donde algunas personas son ricas mientras que otras amargan la falta de recursos para satisfacer sus necesidades básicas y brindarles oportunidades de desarrollo. Dado esto, llevar la agenda ambiental a las personas pobres o en ascenso social en los países en desarrollo que anhelan el consumo es un desafío complejo e inevitable. A través de una investigación exploratoria de carácter bibliográfico y documental, se evidenció que la respuesta a este problema necesariamente pasa por una transformación del paradigma creado por el capitalismo industrial, a través de modelos económicos alternativos. Además, se encontró que, en un escenario marcado por incertidumbres y conflictos, los Objetivos de Desarrollo Sostenible, que conforman la Agenda 2030, constituyen un conjunto esquemático de objetivos alcanzables hacia el desarrollo sostenible, permitiendo su internalización en diferentes contextos, hacia no solo producción y consumo conscientes, sino también la construcción de un mundo mejor.

PALABRAS CLAVE: Desarrollo Sostenible. Consumismo. Principio de Precaución. 


\section{INTRODUÇÃO}

O debate acerca da possibilidade de um modelo global de desenvolvimento sustentável nunca configurou pauta tão urgente e preocupantemente necessária. Ainda que praticamente exista um consenso a respeito da gravidade da situação que envolve a vida na Terra e ações em escala global tenham sido exitosas, como no cumprimento de algumas metas atribuídas aos Objetivos de Desenvolvimento do Milênio (UNITED NATIONS, 2015a), as vozes que se insurgem contra o padrão estabelecido de consumo e descarte, descolado de precauções ambientais e sociais, ainda enfrentam considerável resistência, ameaçando as frágeis conquistas alcançadas até então.

A segunda metade do Século XX foi marcada por uma gama de eventos que enfocaram o esgotamento do planeta, processo iniciado dois séculos antes, com a Revolução Industrial, que transformou radicalmente as relações das pessoas entre si e destas com o meio ambiente.

A primeira grande contestação do modelo de exploração da terra para satisfação das necessidades humanas pode ser encontrada na obra Silent Spring (CARSON, 1962), que questionou o uso de pesticidas na agricultura norte americana, inaugurando uma discussão inédita à época: os impactos danosos à saúde humana de componentes químicos provenientes da alta demanda por produtos do campo para alimentar a população das grandes metrópoles. Na década seguinte, em 1972, o relatório The Limits to Growth, encomendado pelo Clube de Roma a um grupo de pesquisa do Massachusetts Institute of Technology (MIT), obteve impacto mundial - e não necessariamente positivo -, uma vez que, por meio de modelos matemáticos computacionais, sugestionou que a solução para a finitude dos recursos naturais do planeta seria o chamado "crescimento zero". Por isso, o documento recebeu duras críticas: para muitos economistas contemporâneos ao relatório, a utilização dos modelos computacionais seria passível de desconfiança e, segundo estes, os pesquisadores do MIT desconsideraram a ideia de que o progresso tecnológico seria capaz de aumentar a expectativa de vida do planeta (SAES; MYAMOTO, 2012); além disso, para os países em desenvolvimento, como o Brasil, que à época vivia o "milagre econômico", bem como para os chamados Tigres Asiáticos, a ideia de frear o crescimento do PIB e a geração de riquezas advindas da pujança industrial não convenceu, tendo em vista que, até então, "a grande maioria dos países permanecia pobre, com dificuldades de iniciar um processo de crescimento econômico sustentado" (ROMEIRO, 2012, p. 68).

Ainda assim, o debate suscitou uma série de encontros reunindo líderes e pesquisadores de todo o planeta, bem como publicações nesse sentido, com destaque para: a Conferência das Nações Unidas sobre o Meio Ambiente Humano, realizada em Estocolmo, no ano de 1972, em que o ecodesenvolvimento assumiu papel de destaque; o Relatório Brundtland, que conceituou o desenvolvimento sustentável como "aquele que atende às necessidades do presente sem comprometer a possibilidade de as gerações futuras atenderem às suas necessidades" (WCED, 1987, p. 43); e a Conferência das Nações Unidas sobre o Meio Ambiente e o Desenvolvimento, que aconteceu no Rio de Janeiro, em 1992.

Romeiro (2012, p. 70), com base na evolução desse pensamento, traduzido em eventos mundiais e conceituações, e analisando os desdobramentos da corrente científica que 
apostava no progresso técnico como solução para os problemas ambientais, pondera assertivamente:

\begin{abstract}
É interessante notar que vinte anos depois da primeira conferência havia ficado mais claro que o progresso técnico, a varinha mágica dos desenvolvimentistas otimistas, havia sido muito mais eficiente em lidar com o problema do meio ambiente como (a) provedor de matérias-primas, do que no enfrentamento do problema do meio ambiente como (b) provedor de serviços ecossistêmicos: (a) os preços das matérias-primas haviam caído, graças ao progresso técnico na exploração de recursos naturais, na substituição de insumos caros por insumos mais baratos e na eficiência (ecológica) de sua utilização; (b) entretanto, a poluição, a degradação de ecossistemas haviam aumentado apesar do progresso técnico.
\end{abstract}

Dessa forma, atualmente depreende-se que "a maior preocupação talvez não seja o esgotamento dos recursos, mas a poluição decorrente de sua transformação e, por isso, a solução para os principais problemas ambientais requer uma redução voluntária de consumo dos recursos a níveis imprecisos" (SAES; MYAMOTO, 2012). De fato, o relatório "Perspectivas Mundiais de População 2019" prevê que até o ano de 2050 a população global ultrapassará a marca de 9,7 bilhões de pessoas, necessitando de quase três planetas Terra para que sejam proporcionados os recursos naturais necessários a fim de manter o atual estilo de vida da humanidade (NAÇÕES UNIDAS NO BRASIL, 2016; UNITED NATIONS, 2019).

Esse consumo naturalmente gerará resíduos, o que comprometerá ainda mais a resiliência dos ecossistemas. Então, ao admitir que o modelo vigente configura-se como uma bomba-relógio, o Princípio da Precaução dita que

é necessário considerar legítima a adoção por antecipação de medidas relativas a uma fonte potencial de danos sem esperar que se disponha de certezas científicas quanto às relações de causalidade entre a atividade em questão e o dano temido (ROMEIRO, 2001, p. 22).

Sendo assim, a transformação por meio de práticas sustentáveis é urgente, exatamente porque os seres humanos desconhecem os limites do planeta.

Para racionalizar o consumo e formular estratégias no sentido de conferir soluções para essa crise, foram concluídas em agosto de 2015 as negociações que culminaram na adoção, em setembro, dos Objetivos de Desenvolvimento Sustentável (ODS), também conhecidos como Objetivos Globais, por ocasião da Cúpula das Nações Unidas para o Desenvolvimento Sustentável, que reuniu todos os países membros da ONU em sua sede, em Nova lorque.

A partir do exposto, esta pesquisa lançou luz à problemática do consumo face aos limites do planeta, tendo como contexto as aspirações de crescimento econômico de países em desenvolvimento e de populações em ascensão social.

Ressalta-se que o título deste artigo foi escolhido com base na célebre frase do sociólogo Zygmunt Bauman: "A única coisa que podemos ter certeza é a incerteza". Dissertar a respeito do consumismo seria impossível sem compreender a modernidade líquida, teorizada e disseminada por Bauman. No entanto, não há como discordar da ideia de que, caso o consumo 
dos países ricos mantenha-se e seja compartilhado por nações populosas como China, Paquistão, Nigéria e Brasil, não há dúvidas de que a humanidade conhecerá sua ruína em poucas décadas.

\section{OBJETIVO}

O presente artigo objetivou-se a explorar a internalização do Objetivo de Desenvolvimento Sustentável 12 - Produção e consumo conscientes, em contextos de países periféricos em desenvolvimento, cuja demanda, se espelhada no padrão de consumo dos países centrais, pode esbarrar nos limites naturais do planeta, a fim de verificar a situação atual referente a essa temática e evidenciar, na bibliografia, modelos alternativos de ação, capazes de conduzir o pensamento econômico e a lógica da produção a considerarem o meio ambiente como fator chave, e não apenas como externalidade, como prevê a economia neoclássica.

\section{PROBLEMA DE PESQUISA E METODOLOGIA}

Através do objetivo exposto anteriormente, chega-se ao seguinte problema de pesquisa: como levar a pauta ambientalista para pessoas pobres ou em ascensão social nos países em desenvolvimento, que anseiam pelo consumo?

Partindo dessa questão, a metodologia escolhida envolveu a pesquisa exploratória, que, de acordo com Gil (2008, p. 27) "tem como principal finalidade desenvolver, esclarecer e modificar conceitos e ideias, tendo em vista a formulação de problemas mais precisos ou hipóteses pesquisáveis para estudos posteriores", sendo o delineamento da mesma caracterizado como bibliográfico, tendo em vista que a pesquisa foi "desenvolvida a partir de material já elaborado, constituído principalmente de livros e artigos científicos" (GIL, 2008, p. 50).

\section{DISCUSSÃO E RESULTADOS}

De acordo com a Organização das Nações Unidas, em 2015, 50\% da população mundial já vivia em áreas urbanas e a previsão para 2050 é que essa porcentagem se aproxime de $70 \%$ (UNITED NATIONS, 2015b). Essa transição, gradual, mas acentuada nas últimas décadas, reflete a necessidade de políticas capazes de responder às transformações impulsionadas pela vida urbana.

A isso, soma-se a padronização do consumo em escala mundial alavancada pelo capitalismo, através da fetichização de mercadorias, em grande parte descartáveis e produzidas por mão de obra de países emergentes, conduz os seres humanos a um movimento de ampliação da produção de resíduos diretos e indiretos, excedendo a capacidade de absorção do planeta. Para o caso brasileiro, por exemplo, Freitas (2014, p. 111) afirma que:

[...] a mudança no uso do solo da terra e florestas deixou de ser a principal origem de GEE [gases causadores do efeito estufa]. O processo de desenvolvimento econômico associado ao controle do desmatamento aumentou a importância do consumo das famílias como fonte de pressão ambiental. Evitar que este processo ocorra à custa da sustentabilidade é um desafio de largas proporções. 
Essa explanação é possível, em medida considerável, graças ao trabalho de economistas ecológicos, como o romeno Nicolas Georgescu-Roegen (1971), que introduziu o conceito presente nas leis da termodinâmica para explicar que é possível reduzir a quantidade de resíduos por meio do aumento da eficiência ecológica. No entanto, há limites entrópicos intransponíveis a partir de certo ponto: Herman Daly (2004, p. 197) afirma que o "crescimento sustentável é impossível", tendo em vista que esta noção está intrinsecamente ligada ao aumento de tamanho, enquanto o desenvolvimento refere-se a tornar diferente, evoluir. $A$ esses nomes, somam-se Robert Costanza, Joan Martinez-Alier, Paul Ehrlich, Kenneth Boulding, Richard Norgaard e Robert Goodland, questionadores das variadas correntes da economia neoclássica, que, de maneira trivial, reduzem as relações econômicas às trocas entre as firmas e as famílias, relegando ao meio ambiente e às aspirações humanas o papel secundário de apêndice, penduricalho ou externalidade (CAVALCANTI, 2010).

Dessa forma, a primeira tentativa de resposta para o problema evidenciado neste artigo pode ser encontrada na bibliografia referente à Economia Ecológica (EE). No entanto, até o momento não há países que experimentaram uma orientação econômica exclusivamente voltada para essa corrente, ou exemplos de governos em países emergentes que apostaram em soluções alternativas para vencerem o atraso imposto pela posição marginal no globo. Também, no ensino da Economia, a EE não possui protagonismo, bem como outras concepções heterodoxas e alternativas desta ciência (SÖDERBAUM, 2017).

Cabe, então, analisar instrumentos capazes de internalizar a pauta do desenvolvimento sustentável, devidamente orientado para combater ou mitigar os efeitos do modelo perverso de acumulação de renda, emissão de poluentes e degradação dos recursos naturais, próprios do capitalismo industrial. Talvez o mais proeminente destes seja a Agenda 2030, referenciada anteriormente, com seus Objetivos de Desenvolvimento Sustentável.

Os ODS deverão orientar as políticas nacionais e as atividades de cooperação internacional durante os quinze anos subsequentes, portanto, até o ano de 2030, configurando a chamada Agenda 2030, que sucederá e atualizará os Objetivos de Desenvolvimento do Milênio, que compunham a Agenda 21. Consistem em um conjunto de ações e políticas universais e transformadoras de longo alcance, com centro nas pessoas e apoiados em três dimensões: econômica, social e ambiental (NAÇÕES UNIDAS NO BRASIL, 2015). A Figura 1 expõe os ícones oficiais dos ODS, traduzidos para a Língua Portuguesa. 
Figura 1: Quadro de ícones oficiais dos Objetivos de Desenvolvimento Sustentável (ODS) em Língua Portuguesa

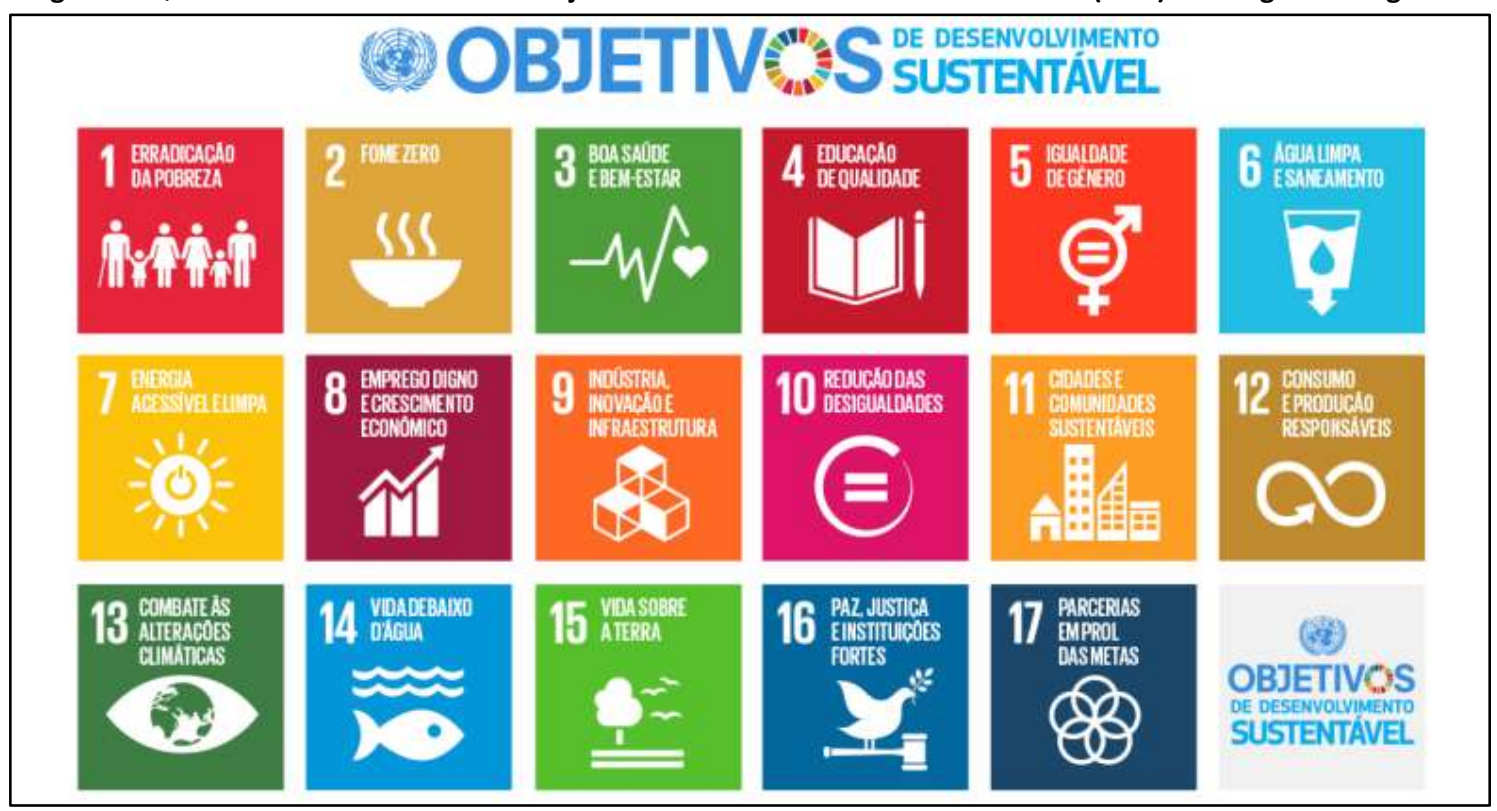

Fonte: Nações Unidas no Brasil, 2015.

Factualmente, a pauta do desenvolvimento sustentável, maturada durante mais de três décadas e sistematizada em 17 objetivos e 169 metas, é capaz de abranger uma série de dimensões, abarcando e extrapolando os tradicionais pilares ambiental, econômico e social. Quando se debate o tema proposto para este artigo, é necessário evitar ao máximo o cinismo de afirmar que as pessoas pobres não devem ascender socialmente, sob o pretexto dos limites do planeta. Ao contrário, o desenvolvimento sustentável prevê a alimentação, a moradia, a equidade de gênero, o trabalho digno e o bem-estar de todas as pessoas. Dessa forma, a ascensão social é almejada nos países periféricos (e, também, para as populações pobres dos países centrais), desde que seja no sentido do desenvolvimento sustentável, limitando o consumo excessivo e o descarte desenfreado de resíduos em regiões abastadas.

$E$, além da supressão das necessidades básicas, há a geração de oportunidades e o oferecimento de liberdades substantivas, como descrito por Sen (2010). Portanto, a reflexão sobre uma Economia estável, do ponto de vista físico, impõe a necessidade de distribuição da riqueza, uma vez que "a pobreza não pode mais ser superada a partir do crescimento econômico" (SAES; MYAMOTO, 2012, p. 61).

Relacionando a Economia Ecológica e a Agenda 2030, Cavalcanti (2010) defende que o termo desenvolvimento sustentável poderia ser entendido apenas como desenvolvimento, sem a necessidade de adjetivá-lo, como transcrito a seguir:

[...] um denominador comum dos praticantes da EE reside na defesa do desenvolvimento (ecologicamente, mas também social e economicamente) sustentável. O que, no fundo, implica qualificar algo que dispensa adjetivos. $\mathrm{Na}$ verdade, se o desenvolvimento não for sustentável - o que significa que seja insustentável -, não será desenvolvimento. Constituirá um processo 
destinado ao fracasso, uma mentira (geralmente encapada pelo credo do crescimento). Em essência, os economistas ecológicos tendem a adotar esta última postura.

Finalmente, para responder a indagação sobre como levar a pauta ambientalista para pessoas pobres ou em ascensão social nos países em desenvolvimento, que anseiam pelo consumo, a literatura analisada sugere uma mudança drástica na compreensão do quanto o planeta pode suportar da ação antrópica e de como a Humanidade pode garantir algo além da mera sobrevivência a todas as pessoas.

Para tanto, a transformação será intrínseca à atuação empresarial, ao marketing, às políticas públicas e, por último, à atuação da sociedade civil, a fim de que os processos produtivos sejam repensados, melhorados e permitam que a produção e o consumo sejam efetivamente conscientes, à medida que questões subjetivas do âmbito social sejam atendidas e permitam aos habitantes de países em desenvolvimento que vivam de maneira digna. Em nações profundamente desiguais, como é o caso do Brasil, enquanto o desperdício (de produtos e, também, de alimentos) é uma realidade para alguns, muitos são excluídos do mercado e não consomem o necessário para uma vida digna.

Silva, Araújo e Santos (2012, p. 98) advertem, com base nesse contexto, que ao tratar de consumo consciente, o consumidor final é o elo mais frágil da cadeia. Por isso, a responsabilidade deve ser redirecionada às grandes corporações

e seu controle sobre o mercado, expressos na produção de estilos de vida, na criação de apetites e de padrões de comportamento, pretensamente inovadores, mas reafirmadores da irracionalidade no uso dos recursos naturais e da subalternidade do conjunto da sociedade face à hipertrofia do mercado.

Ao admitir, portanto, que o capitalismo industrial pautado no consumo desenfreado e a sustentabilidade em suas variadas dimensões são elementos em iminente rota de colisão, a substituição plena da lógica que mantém operante o referido sistema econômico para o desenvolvimento sustentável só poderá ser devidamente transformada mediante o fato de que os argumentos listados neste trabalho - e tantos outros que estão em consonância com eles sejam observados e colocados em prática em tempo hábil, a fim de impedir o colapso do planeta. É exatamente com essa finalidade que trabalham algumas das metas do ODS 12, por exemplo.

Além disso, correntes alternativas como a ecoeficiência, o ecologosimo dos pobres e o ambientalismo, referenciados por Cavalcanti (2010) e a Economia de Francisco, por exemplo, conferem novos ares às Ciências Econômicas e podem servir como impulsionadoras na construção de uma nova forma de relacionamento das pessoas entre si e destas com o meio ambiente.

No caso da Economia de Francisco, um encontro internacional entre jovens estudantes, pesquisadores e ativistas que labutam no campo da Economia, marcado para acontecer em março de 2020 e conclamado pelo Papa Francisco, terá o intuito de desenvolver um novo 
modelo econômico, à luz de documentos como a Evangelii Gaudium e a Laudato Si', que compõem uma parte da Doutrina Social da Igreja (THE ECONOMY OF FRANCESCO, 2019). No segundo documento, o foco encontra-se na chamada ecologia integral, de maneira a incluir as dimensões humanas e sociais (FRANCISCO, 2015).

Sachs (2017, p. 2573) avalia que, além das aproximações entre a mais recente atuação da Igreja Católica na pauta ambiental e a Agenda 2030, o posicionamento eclesiástico é ainda mais ambicioso que os Objetivos de Desenvolvimento Sustentável:

While the Agenda 2030 seeks to repair the existing global economic model significantly, the encyclical calls for a pushing back of economic hegemony and for more ethical responsibility on all levels. While the Agenda 2030 envisions a green economy with social democratic hues, the encyclical foresees a post capitalist-era, based on a cultural shift towards ecosolidarity.

Por ser urgente e representar a esperança de milhões de pessoas que anseiam uma vida digna, a supressão de suas necessidades básicas e a geração de oportunidades para que possam se desenvolver plenamente, observa-se que a pauta do desenvolvimento sustentável e seus desdobramentos abrangem uma profusão de áreas do saber, congregando visões de mundo complementares.

A Figura 2 esquematiza as respostas encontradas para o problema de pesquisa deste artigo, a partir da bibliografia estudada e das referências existentes atualmente. 
Figura 2: Esquematização dos resultados encontrados para o problema de pesquisa proposto

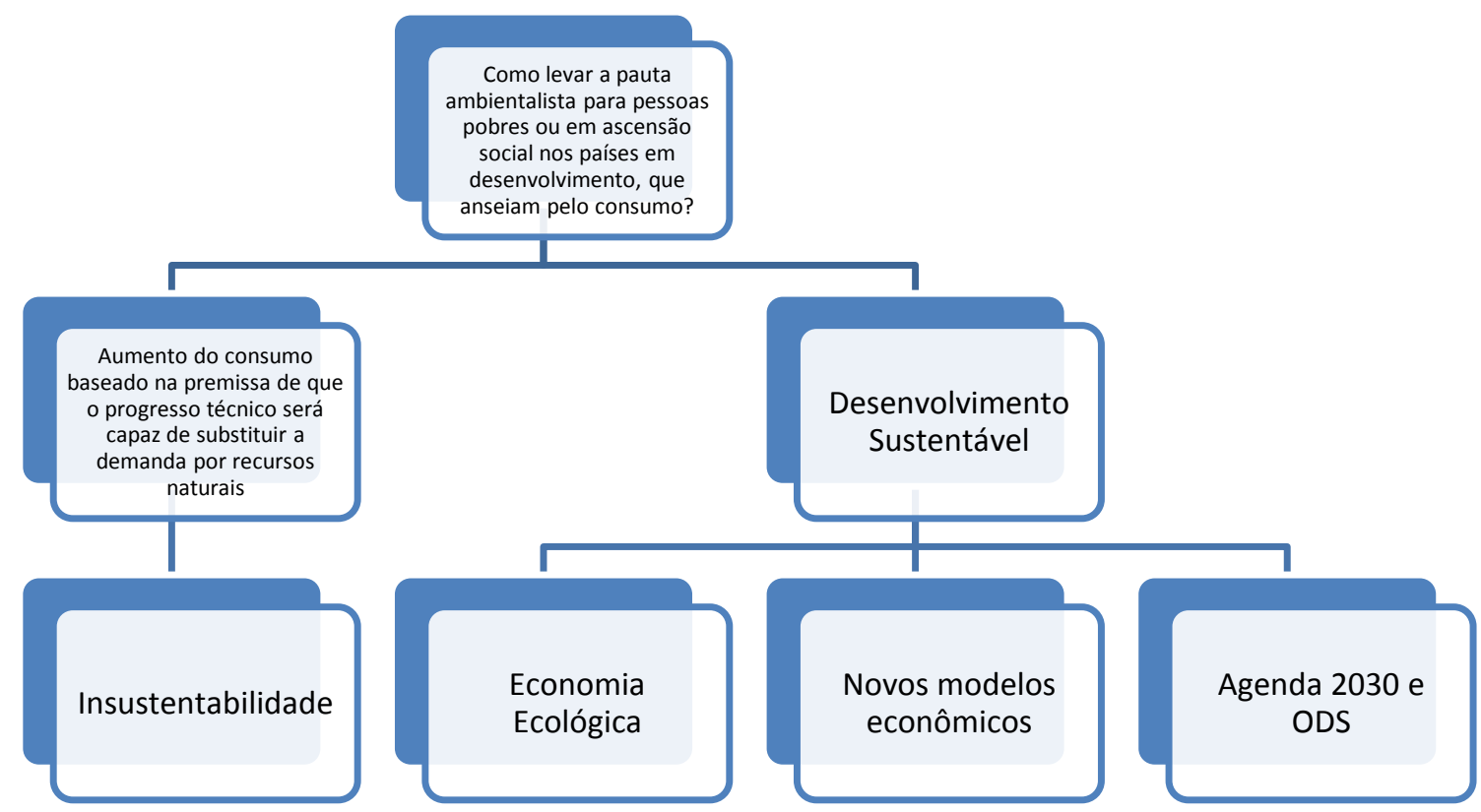

Fonte: Elaborado pelos autores com base nos resultados da pesquisa.

Com isso, torna-se cristalino que a produção consciente e o atendimento às demandas de consumo de populações de baixa renda, excluídas do mercado durante gerações, só serão possíveis por meio de uma profunda transformação de paradigmas, impulsionadas por atores influentes como o Estado e as grandes corporações.

\section{CONSIDERAÇÕES FINAIS}

Este artigo se propôs a verificar, na literatura, como a produção e o consumo conscientes podem se manifestar em contextos de países periféricos em desenvolvimento. Evidenciou-se que a ideia de equiparar o consumo dessas populações com as dos países ricos, tendo em vista que os mesmos puderam crescer economicamente durante décadas, foi superada como possível solução para o problema. Também, a bibliografia apontou para a responsabilidade de governos e empresas na substituição do modelo vigente de produção insustentável e consumismo desigual, algo que demandará uma profunda reestruturação da sociedade.

Nesse sentido, novas estratégias, como a Agenda 2030 e seus Objetivos de Desenvolvimento Sustentável, despontam como alternativas para o capitalismo de consumo, se internalizadas em políticas públicas e subsídios com o intuito de gerar inovação, popularizar novas tecnologias e pressionar as grandes corporações a repensarem suas linhas de produção, subvertendo a ideia de que a responsabilidade é exclusivamente do consumidor final.

Também, destacou-se que, aliados às práticas de produção e consumo conscientes, estão a redução das desigualdades, a geração de oportunidades e liberdades substantivas, de maneira a desconstruir paradigmas forjados pelo capitalismo industrial. Essas pautas encontram campo 
fértil para discussão nos ODS e, também, em novos modelos como a Economia Ecológica e a Economia de Francisco, que estão em consonância com a agenda do desenvolvimento sustentável em escala global, ainda que respeitando suas particularidades e respectivas visões de mundo.

Por isso, em meio às incertezas que permeiam as próximas décadas com relação à sustentabilidade da vida no planeta, a busca pelo desenvolvimento sustentável apresenta-se como uma alternativa certamente indispensável, condição influenciada pela necessidade de estratégias que solucionem os anseios sociais de milhões de pessoas sem que isso esgote os recursos naturais.

Salienta-se, por fim, que em poucos anos a atualização dos Objetivos de Desenvolvimento Sustentável será inevitável, assim como aconteceu com os Objetivos de Desenvolvimento do Milênio. Essa mudança estará condicionada pelo resultado alcançado até 2030 e consistirá em um passo importante para moldar o futuro da Humanidade.

\section{REFERÊNCIAS BIBLIOGRÁFICAS}

ABRAMOVAY, R. Muito além da Economia Verde. Abril: São Paulo, 2012.

CARSON, R. Primavera silenciosa. 2. ed. (Tradução: Raul de Polillo). São Paulo: Melhoramentos, 1969.

CAVALCANTI, C. Concepções da economia ecológica: suas relações com a economia dominante e a economia ambiental. Estudos Avançados, v. 24 (68), p. 53-67. 2010.

COSTANZA, Robert; CUMBERLAND, John; DALY, Herman, GOODLAND, Robert; NORGAARD, Richard. An Introduction to Ecological Economics. Boca Raton, Florida: CRC Press LLC, 1997.

ECONOMIA DE FRANCISCO. Who we are? 2019. Disponível em: https://francescoeconomy.org/who-weare/. Acesso em: 11 out. 2019.

FRANCISCO. Carta encíclica Laudato Si: Sobre o Cuidado da Casa Comum. 1a ed. São Paulo: Paulinas, 2015.

GEORGESCU-ROEGEN, N. The Entropy Law and the economic process. Cambridge MA: Harvard University Press, 1971.

GIL, A. C. Métodos e técnicas de pesquisa social. 6. ed. São Paulo: Atlas, 2008.

DALY, H. Beyond growth. The economics of sustainable development. Boston: Beacon Press, 1996.

FREITAS, L. F. S. Padrão de consumo e pressão ambiental no Brasil. Revista de Economia Contemporânea, Rio de Janeiro, v. 18, n. 1, p. 100-124, abr. 2014. Disponível em: http://www.scielo.br/scielo.php?script=sci_arttext\&pid=S1415-98482014000100100\&lng=en\&nrm=iso. Acesso em: 10 out. 2019.

MEADOWS, D. H. et al. Limites do crescimento: um relatório para o Projeto do Clube de Roma sobre o Dilema da Humanidade. Tradução de I. M. F. Litto; original em língua inglesa: Nova lorque: Universe, 


\section{Periódico Eletrônico}

1972; prefácio de W. Watts e comentário da Comissão Executiva do Clube de Roma. São Paulo: Perspectiva, 1973.

NAÇÕES UNIDAS NO BRASIL. Transformando Nosso Mundo: A Agenda 2030 para o Desenvolvimento Sustentável. 2015. Disponível em: https://nacoesunidas.org/pos2015/agenda2030/. Acesso em: 03 out. 2019.

NAÇÕES UNIDAS NO BRASIL. Banco Mundial: serão necessários 3 planetas para manter atual estilo de vida da humanidade. Ago. 2016. Disponível em: https://nacoesunidas.org/banco-mundial-seraonecessarios-3-planetas-para-manter-atual-estilo-de-vida-da-humanidade/. Acesso em: 10 out. 2019.

ROMEIRO, A. R. Economia ou economia política da sustentabilidade? Texto para discussão

IE/UNICAMP, n. 102, p. 1-28, 2001.

ROMEIRO, A. R. Desenvolvimento sustentável: uma perspectiva econômico-ecológica. Estudos Avançados, São Paulo, v. 26, n. 74, p. 65-92, 2012.

SACHS, W. The Sustainable Development Goals and Laudato si': varieties of Post-Development?. Third World Quarterly, v. 38, n. 12, p. 2573-2587, 2017.

SAES, B. M.; MIYAMOTO, B. C. B. Limites Físicos do Crescimento Econômico e Progresso Tecnológico: o debate The Limits to Growth versus Sussex. Desenvolvimento e Meio ambiente, v. 26, p. 51-68, jul./dez. 2012.

SILVA, M. G.; ARAUJO, N. M. S.; SANTOS, J. S. "Consumo consciente": o ecocapitalismo como ideologia. Revista katálysis, Florianópolis, v. 15, n. 1, p. 95-111, jun. 2012. Disponível em: http://www.scielo.br/scielo.php?script=sci_arttext\&pid=S1414-49802012000100010\&lng=en\&nrm=iso. Acesso em: 10 out. 2019.

SÖDERBAUM, P. Do we need a new economics for sustainable development?. Real-World Economics Review, n. 80, p. 32-44, jun. 2017. Disponível em: http://www.paecon.net/PAEReview/issue80/Soderbaum80.pdf. Acesso em: 14 set. 2019.

UNITED NATIONS. The Millennium Development Goals Report. Jun. 2015a. Disponível em: https://nacoesunidas.org/wp-content/uploads/2015/07/MDG-2015-June-25.pdf. Acesso em: 09 out. 2019.

UNITED NATIONS. World urbanization prospects: the 2014 revision. In: ST/ESA/SER.A/366. UN. Department of Economic and Social. USA, 2015b.

UNITED NATIONS. World Population Prospects 2019. Jun. 2019. Disponível em: https://population.un.org/wpp/. Acesso em: 10 out. 2019. 